\title{
Elaidic Acid, a Trans-Fatty Acid, Enhances the Metastasis of Colorectal Cancer Cells
}

\author{
Hitoshi Ohmori ${ }^{\mathrm{a}}$ Kiyomu Fujii ${ }^{\mathrm{a}}$ Yui Kadochi ${ }^{\mathrm{a}}$ Shiori Mori ${ }^{\mathrm{a}}$ \\ Yukiko Nishiguchi $^{a}$ Rina Fujiwara ${ }^{a}$ Shingo Kishi ${ }^{a}$ Takamitsu Sasaki ${ }^{b}$ \\ Hiroki Kuniyasu $^{a}$ \\ a Department of Molecular Pathology, Nara Medical University, Kashihara, and b Department of Gastroenterological \\ Surgery, Fukuoka University School of Medicine, Fukuoka, Japan
}

\section{Keywords}

Cancer metastasis $\cdot$ Dietary ingredient $\cdot$ Trans-fatty acids

\section{Abstract}

The effects of trans-fatty acids (TFAs) on cardiovascular disorders have been extensively studied, and the effect of TFAs on cancers has recently been recognized. This study examined the effects of elaidic acid (EA), a TFA, on colorectal cancer (CRC) progression. We demonstrated that EA enhanced the growth, survival, and invasion of the CRC cell lines, CT26, and HT29. Tumor growth and metastasis in the lung, liver, and peritoneum were significantly more enhanced in CRC cells treated with EA than those treated with the cis form of $E A$, oleic acid (OA), or vehicle. Spheres of CRC cells were formed at more pronounced numbers in EA-treated cells than in OA-treated cells. Compared to OA, EA treatment also induced expression of the stemness factors, nucleostemin, CD133, and Oct4. Moreover, spheres of EA-treated CRC cells were larger and more proliferative than spheres of OA-treated cells. Oral intake of EA also enhanced liver metastasis and CD133 expression of CRC cells in a dose-dependent manner. EA intake also increased resistance to 5 -fluorouracil. Inhibition of Wnt and ERK1/2 abrogated EA-induced enhance-

\section{KARGER}

(C) 2016 S. Karger AG, Basel

E-Mail karger@karger.com

www.karger.com/pat ment of metastasis. Our findings demonstrate that EA might provide prominent metastatic potential to CRC cells, which shows important implications for the treatment of CRC.

(c) 2016 S. Karger AG, Basel

\section{Introduction}

Trans-fatty acids (TFAs) are a type of unsaturated fatty acid that are widely used in the production of a variety of consumer foods, including margarine, snacks, and shortening in fried fast foods. The trans configuration of unsaturated fatty acids is uncommon in nature (compared to the cis configuration) [1]; therefore, TFAs are generated artificially by hydrogenation using industrial methods [2].

In recent years, the use of TFAs in everyday foods has become a health concern as they are strongly associated with atherosclerosis and ischemic heart disease $[2,3]$. Indeed, TFAs have been shown to increase levels of lowdensity lipoprotein-cholesterol while decreasing levels of high-density lipoprotein-cholesterol [4]. It is alarming that a $2 \%$ increase in daily energy intake associated with TFA consumption translates into a $23 \%$ increase in the

Hiroki Kuniyasu

Department of Molecular Pathology, Nara Medical University 840 Shijo-cho

Kashihara, Nara 634-8521 (Japan)

E-Mail cooninh@zb4.so-net.ne.jp 
risk of death from myocardial infarction or chronic heart disease $[5,6]$. When ingested, TFAs are incorporated into endothelial cells, monocytes/macrophages, or adipocyte cell membranes, or they activate peroxisome proliferatoractivated receptor or retinoid X receptor pathways as ligands, which subsequently activate a series of inflammatory responses resulting in endothelial dysfunction [7].

Elaidic acid (EA, C18:1 trans), which is the trans form of oleic acid (OA, C18:1 cis), is the principal TFA found in partially hydrogenated vegetable oil and margarine [8]. Following ingestion, EA is typically integrated in the plasma membrane of cells [9]. EA has also been shown to induce oxidative stress, for example, an EA rich diet caused oxidative stress in mice due to EA-induced reduction in plasma vitamin E levels [10]. EA can also be incorporated into triglycerides, cholesterol esters, and phospholipids as well as other long-chain fatty acids, such as OA, linoleic acid, and palmitic acid [11]. However, EA shows a low affinity for intestinal lymph triglyceride in comparison with its cis counterpart, OA [12]. Moreover, EA can incorporate into the plasma membrane of steric or palmitic acid and subsequently integrate into triglycerides [13]. The membrane-incorporated EA activates nuclear factor$\kappa \mathrm{B}$ to induce intercellular adhesion molecule- 1 and proinflammatory changes in the aortic endothelial cells, whereas linoleic acid inhibits endothelial cell proliferation [13].

Although EA has received sufficient attention due to its association with a variety of cardiovascular diseases, the effects of EA on colorectal cancer has not been explored. As such, the present study examines the effects of EA on cancer progression and the mechanisms regulating these effects.

\section{Materials and Methods}

\section{Cell Culture and Reagents}

The mouse colon cancer cell line, CT26, was kindly provided by Dr. I.J. Fidler (MD Anderson Cancer Center, Houston, TX, USA) and the human colon cancer cell line, HT29, was purchased from Dainihon Pharmacy Co. (Tokyo, Japan). Cells were routinely maintained in DMEM (Sigma, St. Louis, MO, USA) containing $10 \%$ fetal bovine serum (Sigma) in $5 \% \mathrm{CO}_{2}$ in air at $37^{\circ} \mathrm{C}$. Cell morphology was evaluated daily by microscopic examination. Each cell line was routinely tested for mycoplasma contamination by genomic PCR. Prior to manuscript submission, each cell line was tested for trypan blue exclusion viability and HBV and HCV infection by genomic PCR. Viability was $97 \%$. The results of mycoplasma, HBV, and HCV infection testing were negative.

EA (CAS No.112-79-8; WAKO Pure Chemicals, Osaka, Japan) and OA (CAS No. 112-80-1, WAKO), Wnt inhibitor (IWP3; Milteny Biotech, Bergisch Gladbach, Germany) [14], and extracellular signal-regulated kinase (ERK) inhibitor (3-[2-aminoethyl]-5([4-ethoxyphenyl]methylene)-2,4-thiazolidinedione) (Santa-Cruz Biotechnology, Santa Cruz, CA, USA) were purchased. EA or OA was diluted with $100 \%$ ethanol to a concentration of $0.1 \mathrm{mM}$. For control, $100 \%$ ethanol was used for treatment.

For hypoxic culture, the culture dish was set in the hypoxic pouch with an oxide concentration controller, BIONIX-1 (Sugiyama-Gen Co. Ltd., Tokyo, Japan). Oxide concentration was maintained at $0.2 \%$ during treatment.

\section{Assessment of Cell Growth and Apoptosis}

Cells $\left(1 \times 10^{4}\right.$ per well $)$ were seeded in a 12 -well dish. Cell growth was assessed by 3-(4,5-dimethylthial-2-yl)-2,5-diphenyltetrazalium bromide (MTT) assay or by cell counting with Autocytometer (Sysmex, Kobe, Japan) after $48 \mathrm{~h}$, as previously described [15]. Apoptosis and necrosis were assessed with the Apoptosis/Necrosis Detection Kit (Enzo Life Sciences, Plymouth Meeting, PA, USA). In the kit, apoptotic and necrotic cells were labeled fluorescently by annexin V-EnzoGold and 7-AAD, respectively. A total of 2,000 cells were examined to determine apoptosis or necrosis using a fluorescent microscope (Leica Microsystems, Tokyo, Japan). The experiments were performed in triplicate.

\section{In Vitro Invasion Assay}

A modified Boyden chamber assay was performed to examine the invasion of CRC cells [16]. Following incubation at $37^{\circ} \mathrm{C}$ for $24 \mathrm{~h}$, the filters were carefully removed from the inserts, stained with hematoxylin for $10 \mathrm{~min}$, and mounted on microscopic slides. The number of stained cells in each insert was counted at $\times 100$ magnification. Invasion activity was quantified by calculating the average number of cells per insert well. These experiments were performed in triplicate.

\section{Sphere Assay}

Cells $\left(1 \times 10^{7}\right)$ were seeded onto a bacteriological 3.5-cm dish (Becton-Dickinson Labware, Bedford, MA, USA) in Stem Cell Medium II (Sigma) for 1 week. The number of spheres was counted using dark field microscopy (Nikon, Tokyo, Japan).

\section{Immunohistochemistry}

Spheres were fixed with $10 \%$ buffered formalin for $12 \mathrm{~h}$ at $4{ }^{\circ} \mathrm{C}$ and subsequently embedded in $1 \%$ agar. Tumor tissues were fixed with $10 \%$ buffered formalin for $24 \mathrm{~h}$ at $4^{\circ} \mathrm{C}$, followed by dissection. The specimens were processed in a paraffin-embedded block and $4-\mu \mathrm{m}$ thick sections were cut using a microtome. Consecutive tissue sections were immunohistochemically stained using the immunoperoxidase technique, as described previously [16]. AntiMIB1 antibody and anti-CD133 antibody (DAKO Corp, Carpinteria, CA, USA) were used at a concentration of $0.2 \mu \mathrm{g} / \mathrm{mL}$ following an antibody retrieval method in which the slide was heated in the microwave 3 times, for 15 min each time, in phosphate buffer ( $\mathrm{pH}$ 6.0). Secondary antibodies (Medical and Biological Laboratories, Nagoya, Japan) were used at a concentration of $0.2 \mu \mathrm{g} / \mathrm{mL}$. Next, the specimens were color-developed with diamine benzidine hydrochloride (DAKO) and Meyer's hematoxylin (Sigma) was used for counterstaining. The number of MIB1-positive nuclei were counted and expressed as the mean number of positive nuclei from 30 spheres or 50 high-power fields of tumor specimens. 
Animal Models

$\mathrm{BALB} / \mathrm{c}$ and BALB/cSlc-nu/nu (males, 5 weeks old) were purchased from Japan SLC (Shizuoka, Japan). The mice were maintained according to the institutional guidelines approved by the Committee for Animal Experimentation of Nara Medical University in accordance with the current regulations and standards established by the Ministry of Health, Labor and Welfare. For each experimental group, 5 animals were used.

For the subcutaneous tumor model, CT26 or HT29 cancer cells $\left(1 \times 10^{7}\right.$ cells) suspended with Hank's balanced salt solution (Sig$\mathrm{ma}$ ) were inoculated into the scapular subcutaneous tissue of mice. For analysis of metastasis to the liver, lung, and peritoneum, cancer cells $\left(1 \times 10^{6}\right.$ cells $)$ were inoculated into the spleen, the tail vain, or peritoneal cavity, respectively. EA or OA were administrated intraperitoneally. After 4 weeks, the metastatic status was assessed. For peritoneal metastasis, weights of mesenterium with tumors were measured. For metastases to the liver and lung, the number of tumors at the organ surface was counted.

For sphere-derived subcutaneous tumors, CT26 cell spheres from $1 \times 10^{7}$ treated with EA or OA were collected and suspended to PBS. The suspension was inoculated into the scapular subcutaneous tissue of BALB/c mice. After 2 weeks, tumors were excised to examine.

In the EA oral intake model, BALB/c mice were administrated EA and/or 5-fluorouracil (FU) intragastrically and intraperitoneally, respectively, every 7 days. Mice were euthanized at 4 weeks after inoculation.

Western Blot Analysis

Whole-cell lysates were prepared as described previously [16]. Lysates $(25 \mu \mathrm{g})$ were separated by $12.5 \%$ sodium dodecyl sulfatepolyacrylamide gel electrophoresis (SDS-PAGE), and then electrotransferred onto nitrocellulose filters for immunoblot analysis. The filters were incubated with primary antibodies followed by peroxidase-conjugated IgG antibodies (MBL). Antibodies for tubulin or $\beta$-actin were used to measure the amount of protein loaded per lane (Oncogene Research Products, Cambridge, MA, USA). The immune complex was visualized using a CSA system (DAKO, Carpinteria, CA, USA). Antibodies for nucleostemin (guanine nucleotide binding protein-like 3; NS), MUC1 (Lifescience Bioscience Inc., Seattle, WA, USA), MUC2 (Abgent Inc., San Diego, CA, USA), CDX2, c-Myc, and CD133 (DAKO) were used as primary antibodies.

Statistical Analysis

Statistical analyses of experimental data were performed using the Mann-Whitney U test or the Kruskal-Wallis test with Dunn's multiple comparison test (nonparametric ANOVA). Statistical significance was defined as a two-sided $p$ value of less than 0.05 .

\section{Results}

\section{Pretumoral Effect of EA}

First we examined the effect of EA on cell growth, apoptosis, and invasion in the CT26 and HT29 CRC cell lines (Fig. 1a-c). We showed that EA treatment significantly increased cell growth, antiapoptotic survival, and invasion in a dose-dependent manner in both cell lines.
Next, the effect of EA on tumor growth was examined in CRC cells (Fig. 1d, e). Subcutaneous tumors of CT26 or HT29 cells treated with EA showed a significant increase of tumor growth ( $>3$-fold increase) compared to cells treated with OA or vehicle. The effect of EA on tumor metastasis was then examined in 3 mouse models (Fig. 1f-h): (1) a peritoneal metastasis model by intraperitoneal inoculation, (2) a liver metastasis model by intrasplenic inoculation, and (3) a lung metastasis model by caudal vein inoculation. In these models, EA treatment enhanced tumor metastasis size or number of metastatic foci by $3.2,1.8$, and 3.8 times in the peritoneum, liver, and lung, respectively.

\section{Effect of EA on Cancer Stem Cells}

Recent studies have revealed that cancer stem cells (CSCs) may contribute to metastasis [17]. To assess the effects of EA on CSCs, sphere formation of the cells was analyzed under an anchorage-independent condition cultured in the serum-free stem cell medium (Fig. 2a, b). We show that concurrent EA treatment enhanced sphere formation by 13.7 times compared to OA and vehicle. Pretreatment with EA also significantly increased sphere formation by 5.8 times. Hypoxic conditions are reported to increase stemness in cancer cells [18]. As such, we examined the effects of hypoxic pretreatment in EA-, OAand vehicle-treated cells. We demonstrated that hypoxic conditions increased the number of spheres in vehicle- or OA-treated cells, and this effect was particularly amplified in EA-treated cells.

The expressions of stem cell markers (NS, CD133, and Oct4), intestinal differentiation markers (MUC1, MUC2, and CDX2) [19], and undifferentiation marker (c-Myc) were examined in OA- and EA-treated cells (Fig. 2c, d). EA-treated CT26 cell spheres expressed NS, CD133, and Oct4, whereas vehicle- or OA-treated spheres expressed them at traceable levels (Fig. 2c). In contrast, EA-treated spheres showed low levels of MUC1, MUC2, and CDX2, which were lower than those of vehicle- or OA-treated spheres (Fig. 2d). c-Myc expression was higher in EAtreated spheres than those in vehicle- or OA-treated spheres. The total cell number composing a sphere and the number of $\mathrm{MIB1}(+)$-proliferating cells in a sphere were increased in EA-treated cells compared with vehicle- or OA-treated cells (Fig. 2e, f).

To confirm tumorigenicity of EA-treated cells, which is thought to be one of the cancer stem phenotypes, we also examined the prometastatic effects of EA at various inoculated cell numbers (Fig. $2 \mathrm{~g}$ ). In the peritoneal metastasis model, the $1 \times 10^{3}$ of EA-treated CT26 and HT29
146

Pathobiology 2017;84:144-151

DOI: $10.1159 / 000449205$
Ohmori/Fujii/Kadochi/Mori/Nishiguchi/

Fujiwara/Kishi/Sasaki/Kuniyasu 
Fig. 1. Effects of EA on protumoral properties of CRC cells. a Effect of various concentrations of EA on cell growth in HT29 and CT2 6 cells. b, c Effect of EA ( $35 \mu \mathrm{M})$ on apoptosis and invasion in CRC cells. $\mathbf{d}$, e Growth of subcutaneous CRC cells in mice treated with EA, OA (10 mg/mouse), or vehicle (70\% ethanol-PBS). $\mathbf{f}-\mathbf{h}$ Metastasis of CRC cells in mice treated with EA, OA, or vehicle. $f$ Peritoneal metastasis by intraperitoneal inoculation assessed by weight of the mesenterium. $\mathbf{g}$ Liver metastasis by intrasplenic inoculation assessed by numbers of tumors in the liver. $\mathbf{h}$ Lung metastasis by tail vein inoculation assessed by numbers of tumors in the lung. Error bar, SD from 5 mice in each group.
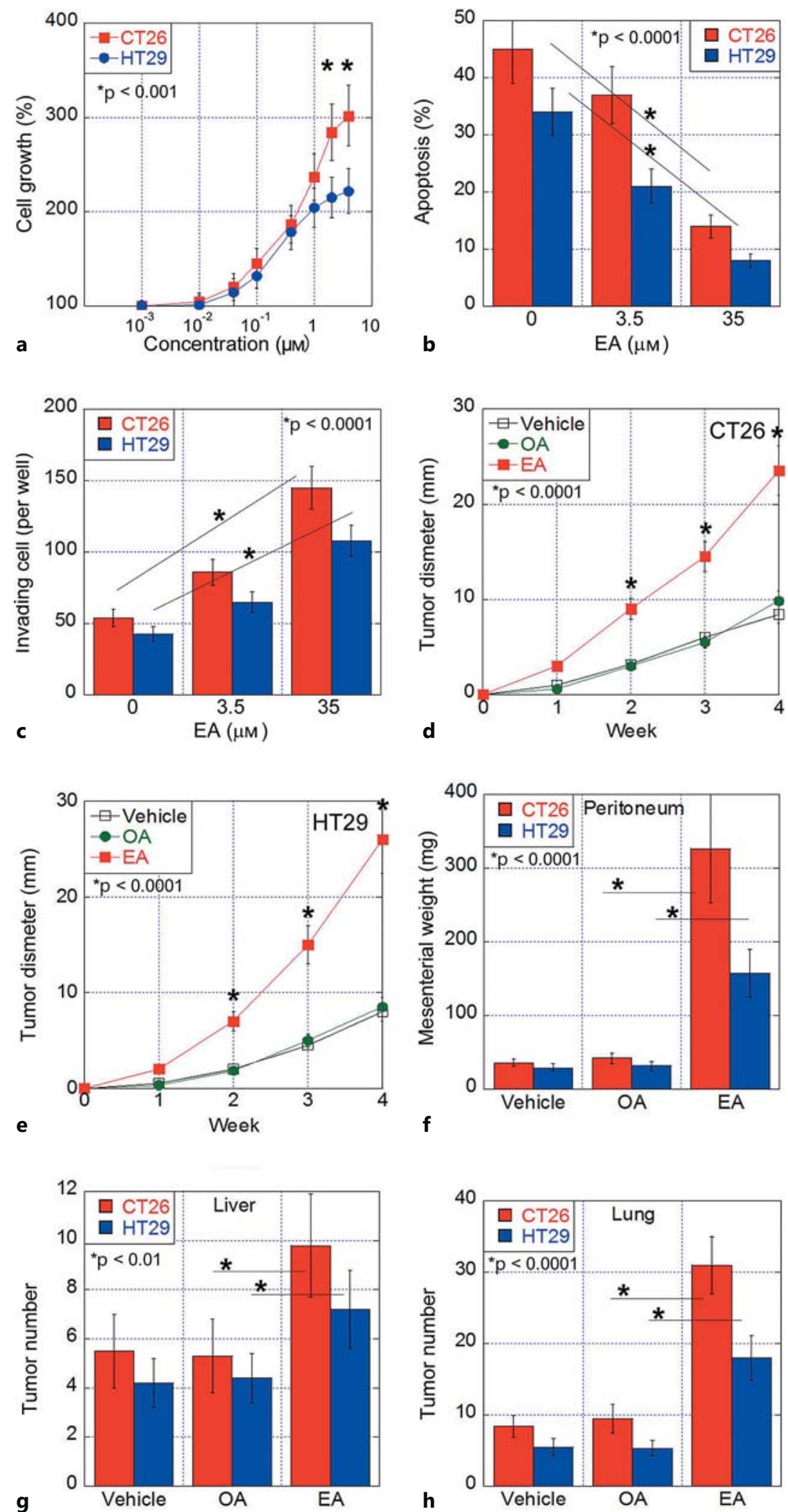
Fig. 2. Effects of EA on stemness of CRC cells. a, b Treatment protocol of spherecultured CT26 cells with pretreatment or hypoxia. Sphere number was compared among cells treated with EA, OA, or vehicle. c, d Expression of stem cell markers in CT26 cells. c Expression of stem cell-associated proteins, NS, CD133, and Oct4, was examined by Western blotting in CT26 cell spheres. d Expression of differentiation-associated proteins, MUC1, MUC2, CDX2, and $\mathrm{c}-\mathrm{Myc}$, was examined by Western blot in CT26 cell spheres. Tubulin served as a loading control. e, $\mathbf{f}$ Number of sphereforming cells and MIB1-labeling index (\%) in CT26 cells treated with EA, OA, or vehicle. g Peritoneal metastasis by CT26 and HT29 cells inoculated with various numbers. $\mathbf{h}$ Expression of differentiation-associated proteins, MUC1, MUC2, and CDX2, was examined by Western blot in subcutaneous tumors derived from EA-treated CT26 cell spheres inoculated to BALB/c mice. Tumors were examined at 2 weeks after inoculation. $\beta$-Actin (ACTB) or tubulin served as a loading control. Each bar or point represents the mean \pm SD of 3 independent experiments or 5 mice in each category.
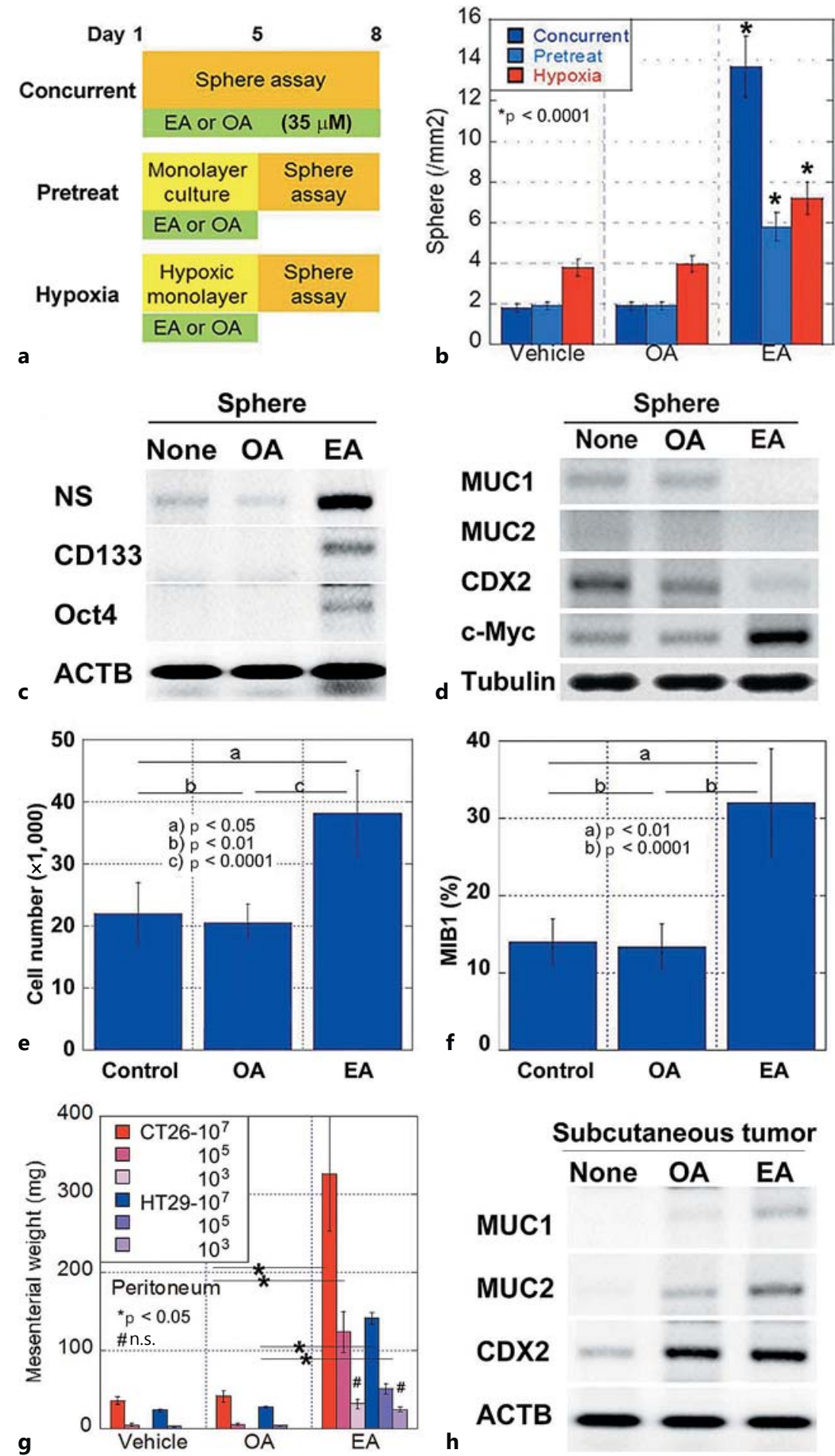
Fig. 3. Effect of oral intake of EA on liver metastasis of CRC cells. a Effect of administration of EA on liver metastasis of CT26 and HT29 cells inoculated into the spleen. EA was administrated intragastrically every 7 days. b Number of CD133-positive cells in the metastatic foci. c Effect of EA on inhibition of metastasis by 5-FU. 5-FU was administrated intraperitoneally every 7 days. d Effect of inhibitors for Wnt signal (IWP3, $0.1 \mu \mathrm{mol} / \mathrm{mouse}$ ) and ERK1/2 (0.5 $\mu \mathrm{mol} / \mathrm{mouse})$ on the liver metastasis. Each bar or point represents the mean \pm SD of 3 independent experiments or 5 mice in each category.
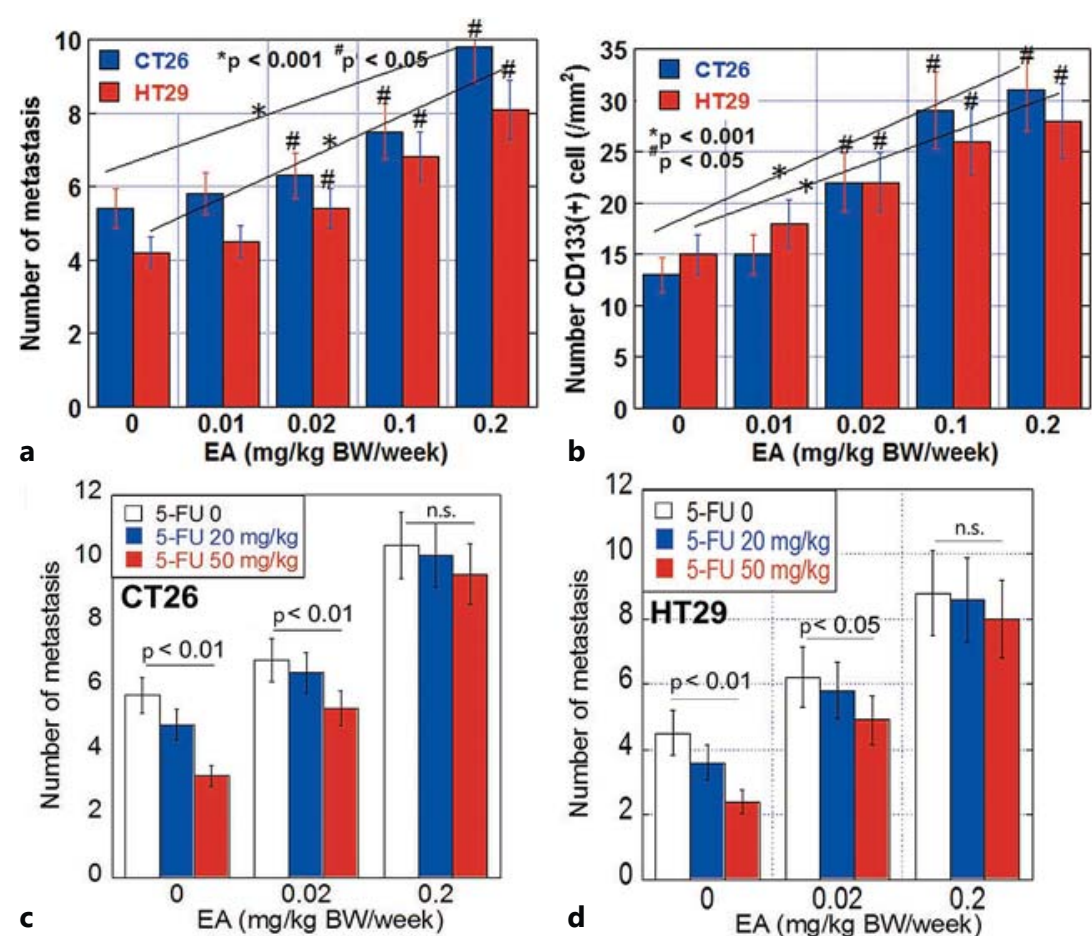

b
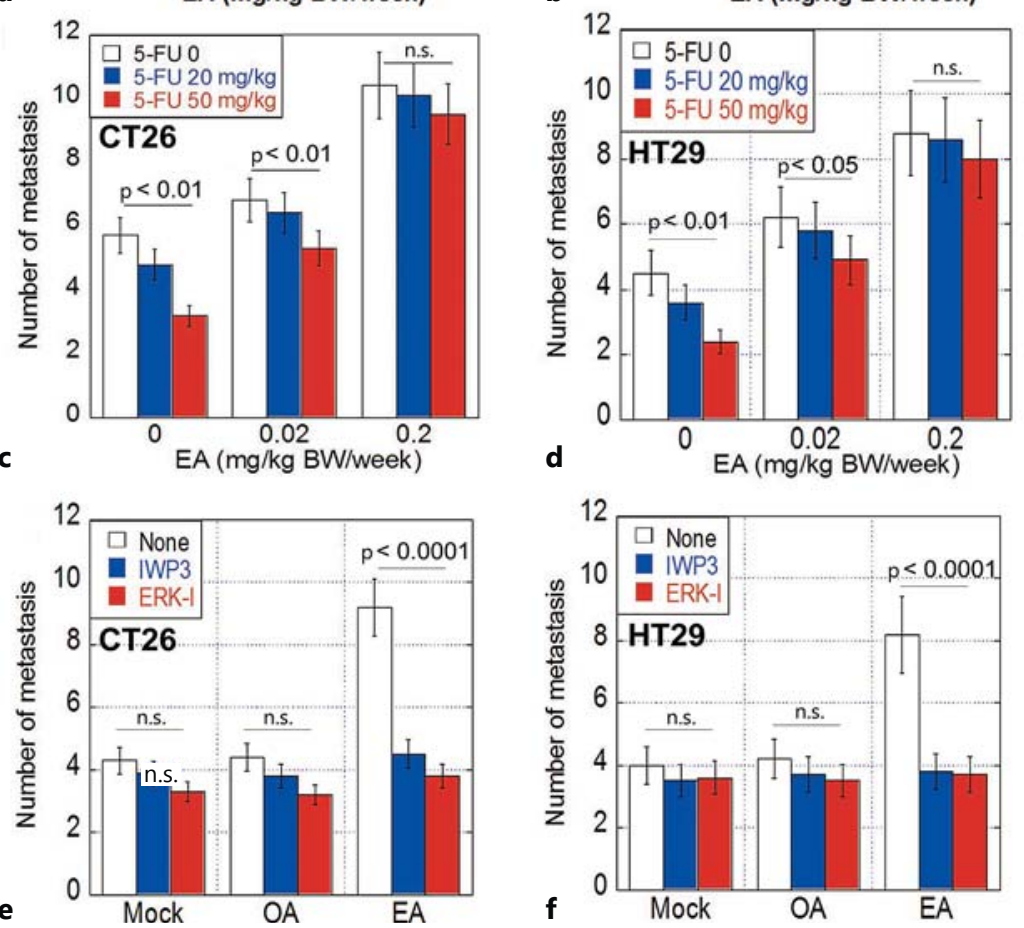

cells formed the similar weight of metastasis to those of the $1 \times 10^{7}$ of OA-treated cells. The $1 \times 10^{5}$ and $1 \times 10^{7}$ of EA-treated cells resulted in more pronounced metastasis than the $1 \times 10^{7}$ of OA-treated cells. We next confirmed production of differentiated peripheral cancer cells from EA-treated cells, which is thought to be one of the cancer stem phenotypes [20] (Fig. 2h). Expression of the intestinal differentiation markers, MUC1, MUC2, and CDX2, was examined in subcutaneous CT26 tumors from EAtreated spheres inoculated. Tumors from EA-treated spheres showed an increase of the differentiation factors in comparison to those of tumors from the vehicle- or OA-treated spheres.

TFA Enhances Metastasis
Effect of Oral Intake of EA on Liver Metastasis of CRC Cells

Since EA is a food ingredient, the effect of EA oral intake was examined using CT26 and HT29 cells (Fig. 3). In the liver metastasis mode, EA intragastric administration enhanced liver metastasis in a dose-dependent manner (Fig. 3a). In the metastatic foci, CD133-positive cells were increased by EA in a dose-dependent manner, which was parallel to the number of liver metastases (Fig. 3b). EA intake also provided CT26 and HT29 cells antichemotherapeutic property (Fig. 3c). Inhibition of the 5-FU-induced antimetastatic effect was associated with EA concentration. Finally, the effect of Wnt and ERK1/2 inhibi- 
tors on metastatic ability was examined (Fig. 3d). Wnt and ERK1/2 inhibitors abrogated EA-induced liver metastasis in comparison with that in mock-treated mice. In contrast, liver metastasis was not affected by inhibition of Wnt or ERK1/2 in OA-treated mice, which showed the same effect as that in mock-treated mice.

\section{Discussion}

In the present study, we investigated the effects of EA on colorectal cancer in vitro by examining CRC cell stemness. Previous studies have shown that TFAs are associated with increased risk of developing breast cancer and nonaggressive prostate cancer [21,22]. The effects of EA on colon carcinogenesis remain controversial. Other studies have argued against these effects by showing that a diet consisting of $25 \%$ EA does not enhance colon carcinogenesis in female rats [23]. However, plasma concentration of EA is higher in colon adenoma patients than that in healthy controls [24]. Moreover, EA administration enhances cancer development in Apc Min/+ mice [25]. As to cancer progression, Ehrlich ascites tumors in EA-fed mice showed higher proliferative rates than those in OA-fed mice and a lower survival rate (decreased by 45\%) [26]. This effect is attributed to the ability of EA to become more easily incorporated into Ehrlich ascites tumor cells and less oxidized than OA [9].

Long-chain fatty acids have been associated with the development and progression of cancer. EA and linoleic acid are major components of the Western diet; however, their roles in cancer development and progression are still unclear. Linoleic acid, a well-known protumoral factor in CRC [27], together with other n-6 fatty acids are metabolized by cyclooxygenase- 2 to generate prostaglandin $E_{2}$, which provokes a state of chronic inflammation $[28,29]$. In return, the reactive oxygen species produced act as genetic mutagens. In addition, a diet rich in linoleic acid and glucose enhances colon carcinogenesis and metastasis in azoxymethane-induced male rats [30].

Our results showed that EA increased stemness of CRC cells. Recently, studies have focused on the stemness of the cancer cells as an indicator of carcinogenesis and metastasis [31]. Dysregulation of normal stem cells results in transformed stem cells, which develop into tumor-initiating cells or CSCs $[32,33]$. Normal stem cell diversity results in CSCs, which promote heterogeneity and plasticity in the progeny [34].

We showed that EA enhanced sphere formation, in which CSCs were enriched lacking colonic differentia- tion. Interestingly, EA-induced spheres showed high proliferative activity in comparison with OA-induced spheres, which suggests that EA-induced CSCs might be proliferating CSCs but not dormant CSCs [35]. EA also provided drug resistance to 5 -FU in a dose-dependent manner. EA-induced drug resistance was provided in 2 types of CRC cell lines, CT26 and HT29, which carry the K-ras mutation (G12D) [36] and BRAF mutation (V600E) [37], respectively. EA-induced drug resistance regardless of the tumor driver gene might be reflected in the common activation of cancer stemness by EA. The present study demonstrates that the protumoral effects of EA are largely associated with the EA-induced alterations in cancer cell stemness.

Thus, CSCs are an essential therapeutic target; however, conventional anticancer therapies are not effective in hindering CSCs $[38,39]$. We inhibited EA-induced metastasis by treatment with inhibition of the Wnt signal and ERK1/2, which suggests that EA-associated stemness might be enhanced through the MAPK-Wnt pathway. Since inhibition of the MAPK-Wnt pathway did not affect liver metastasis in OA-treated mice, the pathway might be preferential to EA. This pathway is found in EGF-induced epithelial-mesenchymal transition in gallbladder cancer cell lines [14]. Research on the factors that regulate CSC growth and metastasis may provide novel and valuable information on CSC targeting in cancer.

Our findings demonstrate the prominent metastatic potential of EA-treated cancer cells. Since EA is a dietary ingredient used widely, the prometastatic feature has important implications for public health. Further, an extensive epidemiological survey is needed for effective intervention.

\section{Acknowledgements}

The authors thank Ms. Tomomi Masutani for expert assistance with the preparation of this manuscript. This work was supported by MEXT KAKENHI Grant No. 14478351, 13200228, 13253395, and 13394212.

\section{Disclosure Statement}

The authors disclose no potential conflicts of interest.
150

Pathobiology 2017;84:144-151 DOI: $10.1159 / 000449205$
Ohmori/Fujii/Kadochi/Mori/Nishiguchi/ Fujiwara/Kishi/Sasaki/Kuniyasu 


\section{References}

1 Martin C, Milinsk M, Visentainer J, Matsushita M, De-Souza N: Trans fatty acid-forming processes in foods: a review. An Acad Bras Cienc 2007;79:343-350.

2 Ganguly R, Pierce GN: Trans fat involvement in cardiovascular disease. Mol Nutr Food Res 2012;56:1090-1096.

3 Bhupathiraju SN, Tucker KL: Coronary heart disease prevention: nutrients, foods, and dietary patterns. Clin Chim Acta 2011;412: 1493-1514.

4 Dashti N, Feng Q, Franklin FA: Long-term effects of cis and trans monounsaturated (18:1) and saturated (16:0) fatty acids on the synthesis and secretion of apolipoprotein A-I- and apolipoprotein B-containing lipoproteins in Hepg2 cells. J Lipid Res 2000;41:1980-1990.

5 Remig V, Franklin B, Margolis S, Kostas G, Nece T, Street JC: Trans fats in America: a review of their use, consumption, health implications, and regulation. J Am Diet Assoc 2010;110:585-592.

6 Mozaffarian D, Aro A, Willett WC: Health effects of trans-fatty acids: experimental and observational evidence. Eur J Clin Nutr 2009; 63(suppl 2):S5-S21.

7 Mozaffarian D: Trans fatty acids - effects on systemic inflammation and endothelial function. Atheroscler Suppl 2006;7:29-32.

8 Food and Drug Administration: FDA takes step to further reduce trans fats in processed foods. 2013. http://www.fda.gov/News Events/Newsroom/PressAnnouncements/ ucm 373939.htm.

9 Awad AB: Uptake and oxidation of elaidic acid by Ehrlich ascites tumor cells. Cancer Biochem Biophys 1981;5:111-117.

10 Cassagno N, Palos-Pinto A, Costet P, Breilh D, Darmon M, Berard AM: Low amounts of trans 18:1 fatty acids elevate plasma triacylglycerols but not cholesterol and alter the cellular defence to oxidative stress in mice. $\mathrm{Br} \mathrm{J}$ Nutr 2005;94:346-352.

11 Vidgren HM, Louheranta AM, Agren JJ, Schwab US, Uusitupa MI: Divergent incorporation of dietary trans fatty acids in different serum lipid fractions. Lipids 1998;33:955962.

12 Bernard A, Echinard B, Carlier H: Differential intestinal absorption of two fatty acid isomers: elaidic and oleic acids. Am J Physiol 1987;253:G751-G759.

13 Harvey KA, Walker CL, Xu Z, Whitley P, Siddiqui RA: Trans fatty acids: induction of a pro-inflammatory phenotype in endothelial cells. Lipids 2012;47:647-657.

14 Sasaki T, Kuniyasu H, Luo Y, Kato D, Shinya S, Fujii K, Ohmori H, Yamashita Y: Significance of epithelial growth factor in the epithelial-mesenchymal transition of human gallbladder cancer cells. Cancer Sci 2012;103: 1165-1171.
15 Kuniyasu H, Yano S, Sasaki T, Sasahira T, Sone S, Ohmori H: Colon cancer cell-derived high mobility group 1/amphoterin induces growth inhibition and apoptosis in macrophages. Am J Pathol 2005;166:751-760.

16 Kuniyasu H, Oue N, Wakikawa A, Shigeishi H, Matsutani N, Kuraoka K, Ito R, Yokozaki H, Yasui W: Expression of receptors for advanced glycation end-products (RAGE) is closely associated with the invasive and metastatic activity of gastric cancer. J Pathol 2002; 196:163-170.

17 Vaiopoulos AG, Kostakis ID, Koutsilieris M, Papavassiliou AG: Colorectal cancer stem cells. Stem Cells 2012;30:363-371.

18 Mimeault M, Batra SK: Frequent gene products and molecular pathways altered in prostate cancer- and metastasis-initiating cells and their progenies and novel promising multitargeted therapies. Mol Med 2011;17:949964.

19 Westgaard A, Schjolberg AR, Cvancarova M, Eide TJ, Clausen OP, Gladhaug IP: Differentiation markers in pancreatic head adenocarcinomas: MUC1 and MUC4 expression indicates poor prognosis in pancreatobiliary differentiated tumours. Histopathology 2009;54: 337-347.

20 Bach SP, Renehan AG, Potten CS: Stem cells: The intestinal stem cell as a paradigm. Carcinogenesis 2000;21:469-476.

21 Kohlmeier L, Simonsen N, van 't Veer P, Strain JJ, Martin-Moreno JM, Margolin B, Huttunen JK, Fernandez-Crehuet Navajas J, Martin BC, Thamm M, Kardinaal AF, Kok FJ: Adipose tissue trans fatty acids and breast cancer in the European community multicenter study on antioxidants, myocardial infarction, and breast cancer. Cancer Epidemiol Biomarkers Prev 1997;6:705-710.

22 Chavarro JE, Stampfer MJ, Campos H, Kurth T, Willett WC, Ma J: A prospective study of trans-fatty acid levels in blood and risk of prostate cancer. Cancer Epidemiol Biomarkers Prev 2008;17:95-101.

23 Hogan ML, Shamsuddin AM: Large intestinal carcinogenesis. I. Promotional effect of dietary fatty acid isomers in the rat model. J Natl Cancer Inst 1984;73:1293-1296.

24 Pickens CA, Lane-Elliot A, Comstock SS, Fenton JI: Altered saturated and monounsaturated plasma phospholipid fatty acid profiles in adult males with colon adenomas. Cancer Epidemiol Biomarkers Prev 2016;25:498506.

25 Molin M, Berstad P, Benth JS, Alexander J, Paulsen JE, Almendingen K: Effect of different degrees of hydrogenated fish oil on intestinal carcinogenesis in Min/+ mice. Anticancer Res 2013;33:477-483.

26 Awad AB: Trans fatty acids in tumor development and the host survival. I Natl Cancer Inst 1981;67:189-192.

27 Kuniyasu H (ed): Linoleic Acid, ed 2. Berlin, Springer, 2008.
28 Zhou S, Wang G, Chen B, Wang P: Effect of dietary fatty acids on tumorigenesis of colon cancer induced by methyl nitrosourea in rats. J Environ Pathol Toxicol Oncol 2000;19:8186.

29 Rao CV, Reddy BS: Modulating effect of amount and types of dietary fat on ornithine decarboxylase, tyrosine protein kinase and prostaglandins production during colon carcinogenesis in male F344 rats. Carcinogenesis 1993; 14:1327-1333.

30 Shimomoto T, Luo Y, Ohmori H, Chihara Y, Fujii K, Sasahira T, Denda A, Kuniyasu H: Advanced glycation end products (AGE) induce the receptor for AGE in the colonic mucosa of azoxymethane-injected Fischer 344 rats fed with a high-linoleic acid and highglucose diet. J Gastroenterol 2012;47:10731083.

31 Sanders MA, Majumdar AP: Colon cancer stem cells: implications in carcinogenesis. Front Biosci 2011;16:1651-1662.

32 Gudjonsson T, Magnusson MK: Stem cell biology and the cellular pathways of carcinogenesis. APMIS 2005; 113:922-929.

33 Chen SY, Huang YC, Liu SP, Tsai FJ, Shyu WC, Lin SZ: An overview of concepts for cancer stem cells. Cell Transplant 2011;20:113120.

34 Tang DG: Understanding cancer stem cell heterogeneity and plasticity. Cell Res 2012;22: 457-472.

35 Skvortsova I, Debbage P, Kumar V, Skvortsov $S$ : Radiation resistance: Cancer stem cells (CSCs) and their enigmatic pro-survival signaling. Semin Cancer Biol 2015;35:39-44.

36 Castle JC, Loewer M, Boegel S, de Graaf J, Bender C, Tadmor AD, Boisguerin V, Bukur T, Sorn P, Paret C, Diken M, Kreiter S, Tureci $\mathrm{O}$, Sahin U: Immunomic, genomic and transcriptomic characterization of CT26 colorectal carcinoma. BMC Genomics 2014;15:190.

37 Lin L, Sabnis AJ, Chan E, Olivas V, Cade L, Pazarentzos E, Asthana S, Neel D, Yan JJ, Lu X, Pham L, Wang MM, Karachaliou N, Cao MG, Manzano JL, Ramirez JL, Torres JM, Buttitta F, Rudin CM, Collisson EA, Algazi A, Robinson E, Osman I, Munoz-Couselo E, Cortes J, Frederick DT, Cooper ZA, McMahon M, Marchetti A, Rosell R, Flaherty KT, Wargo JA, Bivona TG: The Hippo effector YAP promotes resistance to RAF- and MEKtargeted cancer therapies. Nat Genet 2015;47: 250-256.

38 Todaro M, Francipane MG, Medema JP, Stassi G: Colon cancer stem cells: promise of targeted therapy. Gastroenterology 2010;138: 2151-2162.

39 Botchkina G: Colon cancer stem cells - from basic to clinical application. Cancer Lett 2013; 338:127-140. 